\title{
A 16-week intervention on mood and life quality in elderly: testing two exercise programs
}

\section{Una intervención de 16 semanas sobre el estado de ánimo y la calidad de vida en ancianos: probar dos programas de ejercicio}

\section{Uma intervenção de 16 semanas sobre humor e qualidade de vida em idosos: testando dois programas de exercício}

\author{
Oliveira, B.R.R. ${ }^{1}$, Matos, I.C. ${ }^{2}$, Maranhão Neto, G.A. ${ }^{3}$, Rodrigues, F.,5, Monteiro, D. ${ }^{5,6}$, Lattari, E. ${ }^{2}$, \\ Machado, S. $^{2,7,8}$ \\ ${ }^{1}$ Department of Physical Education, Federal Rural University of Rio de Janeiro, Seropédica, RJ, Brazil \\ ${ }^{2}$ Laboratory of Physical Activity Neuroscience, Physical Activity Sciences Postgraduate Program, \\ Salgado de Oliveira University (UNIVERSO), Niterói, RJ, Brazil \\ ${ }^{3}$ Kardiovize Brno 2030, St. Anne's University Hospital Brno, International Clinical Research Center, \\ Brno, Czech Republic \\ ${ }^{4}$ Sport Science School of Rio Maior, ESDRM-IPSantarém, Rio Maior, Portugal; Life Quality Research \\ Center (CIEQV), Rio Maior, Portugal \\ ${ }^{5}$ Research Center in Sports Science, Health and Human Development (CIDESD) \\ ${ }^{6}$ ESECS, Polytechnic Institute of Leiria, Leiria, Portugal \\ ${ }^{7}$ Laboratory of Physical Activity Neuroscience, Neurodiversity Instituto, Queimados-RJ, Brazil \\ ${ }^{8}$ Intercontinental Neuroscience Research Group, Rio de Janeiro, Brazil
}

\begin{abstract}
The purpose was to examine the effects of strength training program (STP) and multi-component training program (MTP) on mood states in physically active elderly. Thirty Brazilian elderly (female $=21$; male $=9$ ) aged between 65 and 75 years (66.9 \pm 4.1 ) with Body Mass Index (BMI) ranging from 25.6 to $31.0 \mathrm{~kg} / \mathrm{m}^{2}$ $(28.3 \pm 1.2)$, were enrolled for research. The elderly were randomly assigned into two groups: Strength Training Program $\left(\mathrm{STP}\right.$; age $=66.7 \pm 4.4$ years, $\left.\mathrm{BMI}=28.2 \pm 1.3 \mathrm{~kg} / \mathrm{m}^{2}\right)$ and Multi-Component Program $(\mathrm{MTP}$; age $=67.1 \pm 3.9$ years, $\mathrm{BMI}=28.5 \pm 1.0 \mathrm{~kg} / \mathrm{m}^{2}$ ). STP group performed three 1-hour sessions per week, working at a range of 3 sets, 8-10 repetitions, and 2-minute recovery between sets and exercises. MTP group performed two different types of exercise sessions: a) 50 minutes of Zumba $\bigodot$, followed by 5-10 minutes of dynamic stretching exercises; b) 40 minutes of body-weight dynamic and static exercises, as well as agility and balance movements. The Profile of Mood States (POMS) was applied to assess mood at baseline and post-intervention. No significant interaction or main effect for group and time was showed for six factors of the POMS. However, the magnitude-based inference showed that MTP is likely beneficial to reduce fatigue. On the other hand, MTP is possibly harmful to increase confusion and to reduce vigor when
\end{abstract}




\section{Exercise, mood and life quality in eldely}

compared to STP. In practical terms, we can conclude that older people physically active seems to attain an adaptation in mood responses minimizing the additional effects of STP and MTP.

Keywords: resistance training, multimodal training, mood, older adults.

\section{RESUMEN}

El objetivo era examinar los efectos del programa de entrenamiento de fuerza (STP) y el programa de entrenamiento de componentes múltiples (MTP) en los estados de ánimo en ancianos físicamente activos. Treinta ancianos brasileños (mujeres $=21$; hombres $=9$ ) con edades comprendidas entre 65 y 75 años $(66.9 \pm 4.1)$ con un índice de masa corporal (IMC) que varía de 25.6 a $31.0 \mathrm{~kg} / \mathrm{m} 2$ (28.3 \pm 1.2$)$, se inscribieron para la investigación. Los ancianos fueron asignados aleatoriamente en dos grupos: Programa de entrenamiento de fuerza ( $\mathrm{STP}$; edad $=66.7 \pm 4.4$ años, $\mathrm{IMC}=28.2 \pm 1.3 \mathrm{~kg} / \mathrm{m} 2$ ) y Programa de componentes múltiples $(\mathrm{MTP}$; edad $=67.1 \pm 3.9$ años, $\mathrm{IMC}=28.5 \pm 1,0 \mathrm{~kg} / \mathrm{m} 2)$. El grupo STP realizó tres sesiones de 1 hora por semana, trabajando en un rango de 3 series, 8-10 repeticiones y 2 minutos de recuperación entre series y ejercicios. El grupo MTP realizó dos tipos diferentes de sesiones de ejercicio: a) 50 minutos de Zumba@, seguidos de 5-10 minutos de ejercicios de estiramiento dinámico; b) 40 minutos de ejercicios dinámicos y estáticos de peso corporal, así como movimientos de agilidad y equilibrio. El perfil de estados de ánimo (POMS) se aplicó para evaluar el estado de ánimo al inicio y después de la intervención. No se mostró interacción significativa o efecto principal para el grupo y el tiempo para seis factores del POMS. Sin embargo, la inferencia basada en la magnitud mostró que MTP es probablemente beneficioso para reducir la fatiga. Por otro lado, MTP es posiblemente perjudicial para aumentar la confusión y reducir el vigor en comparación con STP. En términos prácticos, podemos concluir que las personas mayores físicamente activas parecen lograr una adaptación en las respuestas del estado de ánimo, minimizando los efectos adicionales de STP y MTP.

Palabras clave: entrenamiento de resistencia, entrenamiento multimodal, estado de ánimo, adultos mayores.

\section{RESUMO}

O objetivo foi examinar os efeitos do programa de treinamento de força (STP) e do programa de treinamento com múltiplos componentes (MTP) nos estados de humor em idosos fisicamente ativos. Trinta idosos brasileiros ( de massa corporal (IMC) variando de 25,6 a $31,0 \mathrm{~kg} / \mathrm{m} 2(28,3 \pm 1,2)$ foram incluídos na pesquisa. Os idosos foram divididos aleatoriamente em dois grupos: Programa de Treinamento de Força (STP; idade $=66,7 \pm$ 4,4 anos, IMC $=28,2 \pm 1,3 \mathrm{~kg} / \mathrm{m} 2)$ e Programa Multi-Componente $(\mathrm{TMF}$; idade $=67,1 \pm 3,9$ anos, $\mathrm{IMC}=$ $28,5) 1,0 \mathrm{~kg} / \mathrm{m} 2$ ). O grupo STP realizou três sessões de 1 hora por semana, trabalhando em uma série de 3 séries, 8 a 10 repetições e recuperação de 2 minutos entre séries e exercícios. O grupo MTP realizou dois tipos diferentes de sessões de exercícios: a) 50 minutos de Zumba $\odot$, seguidos de 5 a 10 minutos de exercícios dinâmicos de alongamento; b) 40 minutos de exercícios estáticos e dinâmicos de peso corporal, bem como movimentos de agilidade e equilíbrio. O perfil dos estados de humor (POMS) foi aplicado para avaliar o humor na linha de base e pós-intervenção. Nenhuma interação significativa ou efeito principal para o grupo e o tempo foi demonstrado para seis fatores do POMS. No entanto, a inferência baseada em magnitude mostrou que a MTP é provavelmente benéfica para reduzir a fadiga. Por outro lado, o MTP é possivelmente prejudicial para aumentar a confusão e reduzir o vigor quando comparado ao STP. Em termos práticos, podemos concluir que as pessoas idosas fisicamente ativas parecem atingir uma adaptação nas respostas de humor, minimizando os efeitos adicionais do STP e MTP.

Palavras-chave: treinamento resistido, treinamento multimodal, humor, idosos. 


\section{Oliveira et al.}

\section{INTRODUCTION}

Older people tend to be more vulnerable to multiple chronic conditions and disabilities, marked by decrements in muscle mass (Marzetti et al., 2017), which may compromise muscular strength, balance, and gait. In addition to physical variables, cognitive impairments may be generated by aging (Seitz, Adunuri, Gill, \& Rochon, 2011), contributing to an increase in the prevalence of mood disturbance. In order to mitigate these effects, physical exercise has been pointed as essential for older adults by several studies (Shawn M Arent, Daniel M Landers, \& Jennifer L Etnier, 2000). In fact, the past literature has demonstrated that exercise in older adults can minimize the effect of physical decline (Buch et al., 2017), cognitive abilities (Bherer, 2015), and positive mood benefits (McLafferty, Wetzstein, \& Hunter, 2004).

With respect to the mood state, a metaanalytic review (Shawn M Arent et al., 2000) concluded that exercise (considering only aerobic and strength training as interventions) is associated with significant improvements in the mood of the older adults. Studies focusing only on the effects of the strength training on the mood state in healthy older adults have shown positive benefits (Kekalainen, Kokko, Sipila, \& Walker, 2018). For example, one study showed that 12weeks of strength training program (STP) of high and low intensities resulted in positive mood changes in the health sedentary older adults (Tsutsumi, Don, Zaichkowsky, \& Delizonna, 1997). Part of the literature has theorized that the improvements in mood states of older adults are related to the initial physical improvements provided by strength training (Kekalainen et al., 2018). On the other hand, the mood improvements in healthy older adults provided by strength training may be associated with a "more enjoyable experience" (Tsutsumi et al., 1998). Thereby, a more enjoyable experience, as a part of the physical training, appears to be especially important when the goal is to improve the mood of the older adults.
Given the above, the existing literature has advocated for the use of a multi-component training program (MTP) to improve cognitivemotor abilities in older adults (Levin, Netz, \& Ziv, 2017). The MTP consists of the combination of the two or more types of physical training (Levin et al., 2017). The MTP has also been shown to benefit overall mood with older adults (Piccirilli, Pigliautile, Arcelli, Baratta, \& Ferretti, 2019). However, despite the positive effect of MTP on mood in older adults, the several possibilities to prescribe MTP may difficult the generalization of this finding (Eggenberger, Theill, Holenstein, Schumacher, \& de Bruin, 2015). Besides that, the physical exercise components associated with cognitive training may increase these effects on mood state in older adults (Eggenberger et al., 2015). Moreover, previous studies on this subject did not compare STP and MTP using mood as the primary outcome, as previously demonstrated by (Levin et al., 2017; Piccirilli et al., 2019). In this context, the direct comparison of STP and MTP may be interesting, considering that STP is recognized as a way to improve the mood responses of older adults (McLafferty et al., 2004).

It seems that the exercise prescription focuses primarily on reducing the mood decline occurred with aging. However, exercise programs may not only prevent but also improve mood in older adults (Shawn M Arent et al., 2000). In contrast, chronic investigations on the mood aspects of the elderly in STP or MTP are scarce. The results of studies could provide new insights on how to create effective training protocols as a way to increase positive mood states in the elderly. Due to the increase of the MTP as an approach for exercise prescription, it is interesting to understand its effects on the mood of the older adults. Therefore, the purpose of the current study was to examine the effects of an STP and MTP on mood states in physically active elderly. According to past literature, we hypothesized that both training protocols would decrease negative mood states and increase positive mood states 


\section{Exercise, mood and life quality in eldely}

contributing to the reduction of total mood disturbance.

\section{MATERIAL AND METHODS}

\section{Participants}

In total, 30 Brazilian elderly (female $=21$; male $=9)$ aged between 65 and 75 years, $(66.9 \pm$ 4.1) with Body Mass Index (BMI) ranging from 25.6 to $31.0 \mathrm{~kg} / \mathrm{m}^{2}(28.3 \pm 1.2)$, were enrolled for research. Sample was split randomly even into two groups: Strength Training Program (STP; age $=66.7 \pm 4.4$ years, BMI $=28.2 \pm 1.3 \mathrm{~kg} / \mathrm{m}^{2}$ ) and Multi-Component Program (MTP; age $=67.1 \pm$ 3.9 years, $\left.\mathrm{BMI}=28.5 \pm 1.0 \mathrm{~kg} / \mathrm{m}^{2}\right)$. For inclusion, participants needed to be aged $\geq 60$ and $\leq 80$ years, and have been physically active for the past six months in any exercise modality. Participants were excluded for analysis if they: a) had dropped-out from the intervention program; b) 2 had failed two consecutive training sessions; c) had acquired a chronic disease during intervention; d) had a musculoskeletal injury, and e) had blood pressure $\geq 140$ x $90 \mathrm{mmHg}$.

All participants were initially informed about the procedures and signed a free and informed consent form, according to Norms for Conducting Research in Humans (CNS resolution 466/2012). The study was approved by the Human and Animal Research Ethics Committee of the Salgado de Oliveira University.

\section{Experimental procedures}

The study was conducted in three phases: (1) baseline assessment; (2) experimental sessions; (3) post-intervention assessment. At baseline and post-intervention, the Profile of Mood States (POMS) was applied in order to assess mood profile (Viana, Almeida, \& Santos, 2001). POMS has been used in several contexts, presenting validity and applicability to measure mood states (Viana et al., 2001). During the experimental sessions, the elderly performed 48 sessions (approximately 16-weeks, $3 \mathrm{x} /$ week) of either STP or MCP protocol, with 48-hour rest intervals between sessions. Training sessions were conducted and supervised by a professional exercise physiologist, granting safety and care to participants.

\section{Mood Assessment}

The Brazilian version of the Profile of Mood States (POMS) Portuguese-Brazilian version (Viana et al., 2001) was used to assess six factors: Tension-Anxiety (T), DepressionDejection (D), Anger-Hostility (A), VigorActivity (V), Fatigue-Inertia (F), and ConfusionBewilderment (C). The short version consists of 42-items that describe moods, to which the participants respond on a 5-point scale that ranges from "Not at all" (0) to "Extremely" (4). The factors can be grouped into two dimensions: i) negative considering $\mathrm{T}, \mathrm{D}, \mathrm{H}, \mathrm{F}$, and $\mathrm{C}$; ii) positive considering $\mathrm{V}$. The total mood disturbance (TMD) is calculated by summing negative factors and then subtracting the positive factor score.

\section{Strength Training Program (STP)}

One week prior to the exercise intervention protocol, the exercise physiologist taught all participants how to maneuver the resistance machine and tailor the resistance load. The elderly in the STP performed three 1-hour sessions per week, working at a range of 3 sets and 8-10 repetitions. A 2-minute recovery was given between sets and exercises, and intensity was adapted every to session to participants with higher performed repetitions. The STP consistent in multiarticular movements, in the following order: seated chest press, leg press, seated row, leg extension, shoulder press, leg curl, calf raise, and seated crunch. Before STP, warm-up was performed on the cycle ergometer at a 60RPM cadency and $55 \%$ of Heart Rate Reserve (HRR) for approximately 10 minutes. After STP, cooldown was conducted by the exercise physiologist using dynamic stretching exercises for about 10 minutes. Each training session lasted nearly 60 minutes.

\section{Multi-Component Program (MTP)}




\section{Oliveira et al.}

Similar to STP, the MTP consisted of three sessions per week. However, in this program, the elderly had two different types of exercise session performed alternately throughout the exercise program: a) 50 minutes of Zumba $\odot$, a fitness exercise program, was performed followed by 5-10 minutes of dynamic stretching exercises; b) nearly 40 minutes of body-weight dynamic and static exercises, as well as agility and balance movements were done. The warm-up consisted of 15 minutes of gait at an intensity between 5-6 points based on Ratings of Perceived Exertion (RPE - CR10), and cool-down lasted 510 minutes of dynamic stretching exercises.

\section{Statistical analysis}

Descriptive statistics (mean and standard deviation) were calculated for variables at baseline and post-intervention (see Table 1). At baseline, homogeneity and normality were tested using the Levene's and Shapiro - Wilk tests, respectively. After check data normality, an ANOVA two-way $2 \times 2$ (group x time) was performed to compare POMS. The SPSS v. 25 was used to perform the analyses. The level of significance was set at $p \leq 0.05$. In addition, an effect size analysis was performed to compare STP and MTP after both interventions. The effect size was interpreted as suggested by (Cohen, 1988) considering the following classification: Small (0.20 - 0.49); Moderate $(0.50-0.79)$; and Large (> 0.80). Also, a magnitude-based inference was performed in order to estimate the chances of benefits, harm, or indifference between exercise conditions for each variable (Batterham \& Hopkins, 2005).

\section{RESULTS}

All mood states at baseline demonstrated homogeneity of variance $(p=0.13)$ and data normality $(p=0.08)$. The analysis did not show either significant main effects or interactions for both group and time factors in the TMD (interaction $-\mathrm{F}_{(1,14)}=.412, \mathrm{p}=.531$; group $-\mathrm{F}_{(1}$, 14) $=1.110, \mathrm{p}=.310 ;$ time $-\mathrm{F}_{(1,14)}=1.957, \mathrm{p}$ $=.184$ ), confusion (interaction $-\mathrm{F}_{(1,14)}=.001, \mathrm{p}$
$=.970 ;$ group $-\mathrm{F}_{(1,14)}=3.490, \mathrm{p}=.083$; time $-\mathrm{F}_{(1,}$ $14)=.225, \mathrm{p}=.642)$, depression (interaction $-\mathrm{F}_{(1}$, $14)=.224, \mathrm{p}=.643$; group $-\mathrm{F}_{(1,14)}=.799, \mathrm{p}=.386$; time $-\mathrm{F}_{(1,14)}=.490, \mathrm{p}=.496$ ), fatigue (interaction $-\mathrm{F}_{(1,14)}=1.976, \mathrm{p}=.182$; group $-\mathrm{F}_{(1,14)}=.195, \mathrm{p}$ $=.665$; time $\left.-\mathrm{F}_{(1,14)}=4.322, \mathrm{p}=.056\right)$, hostility (interaction $-\mathrm{F}_{(1,14)}=.156, \mathrm{p}=.699$; group $-\mathrm{F}_{(1 \text {, }}$ 14) $=1.583, \mathrm{p}=.229$; time $\left.-\mathrm{F}_{(1,14)}=.543, \mathrm{p}=.473\right)$, tension (interaction $-\mathrm{F}_{(1,14)}=1.312, \mathrm{p}=.271$; group $-\mathrm{F}_{(1,14)}=1.573, \mathrm{p}=.230$; time $-\mathrm{F}_{(1,14)}$ $=.024, \mathrm{p}=.878$ ), and vigor (interaction $-\mathrm{F}_{(1,14)}$ $=.326, \mathrm{p}=.577 ;$ group $-\mathrm{F}_{(1,14)}=.160, \mathrm{p}=.695$; time $\left.-\mathrm{F}_{(1,14)}=2.333, \mathrm{p}=.149\right)$. The mean and standard deviation values of POMS questionnaire are presented in table 1 .

Table 1. Descriptive results of POMS.

\begin{tabular}{ccccccccc}
\hline & \multicolumn{8}{c}{ Condition } \\
\cline { 2 - 9 } POMS & \multicolumn{9}{c}{ STP } & \multicolumn{3}{c}{ MTP } \\
\cline { 2 - 9 } Factors & \multicolumn{2}{c}{ Pre } & \multicolumn{2}{c}{ Post } & \multicolumn{3}{c}{ Pre } \\
\cline { 2 - 9 } & M & SD & M & SD & M & SD & M & SD \\
\cline { 2 - 9 } TMD & 126.7 & 22.6 & 124.9 & 10.9 & 124.0 & 23.4 & 115.4 & 13.1 \\
Tension & 8.2 & 2.8 & 8.4 & 2.8 & 9.2 & 2.4 & 7.7 & 3.1 \\
Hostility & 7.2 & 6.2 & 5.8 & 4.3 & 6.8 & 5.1 & 4.4 & 3.7 \\
Fatigue & 8.6 & 5.5 & 10.1 & 5.6 & 7.6 & 6.5 & 4.9 & 3.8 \\
Vigor & 10.8 & 4.7 & 11.1 & 4.2 & 13.2 & 5.0 & 11.9 & 4.1 \\
Confusion & 8.3 & 3.6 & 6.6 & 2.6 & 8.6 & 4.0 & 7.0 & 2.6 \\
Depression & 4.9 & 4.9 & 4.8 & 5.5 & 4.8 & 4.2 & 3.3 & 2.7 \\
\hline
\end{tabular}

STP - strength training program; MTP - multi-component training program; M - mean; SD - standard deviation

The magnitude-based inference results are presented in figure 1 . These results indicated that MTP is likely beneficial to reduce fatigue. On the other hand, MTP is possibly harmful to increase confusion and to reduce vigor when compared to STP.

\section{DISCUSSION}

The objective of this study was to measure the impact of a 16-week intervention on mood state in the elderly, testing two exercise programs (STP and MCP). The initial hypothesis that both exercise interventions would have a positive impact on mood in the elderly was not confirmed. 


\section{Exercise, mood and life quality in eldely}

However, magnitude-based inference showed a considerable effect on fatigue factor, indicating that MTP reduced fatigue from pre-to-post when compared to STP.
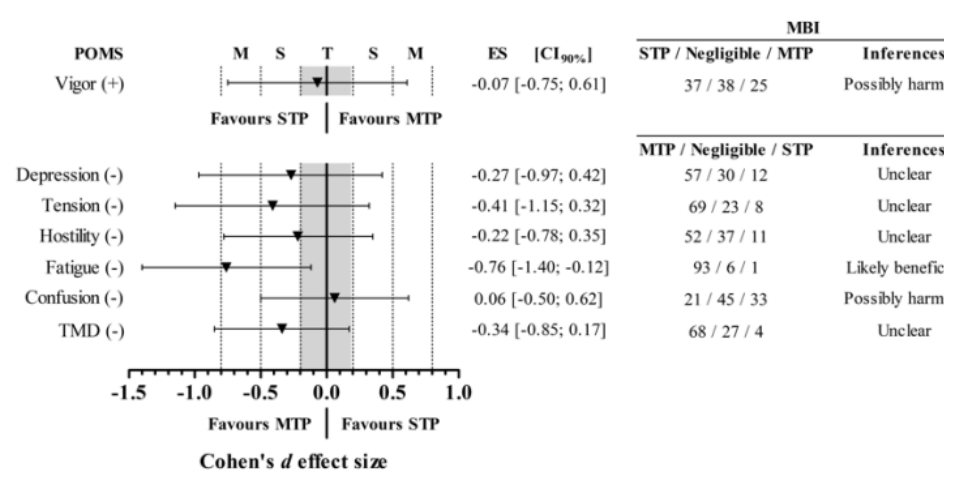

Figure 1. Inference results for POMS.

In general, older adults are highly susceptible to develop negative mood responses due to several factors, such as alterations in brain chemistry, stress, work retirement, and others (USDHHS, 2017), which may cause depression and other mood disturbances with several clinical implications (Agüera-Ortiz et al., 2020). In this sense, exercise may contribute to improving mood responses, and the magnitude of these responses is dependent on the exercise configuration (S. M. Arent, D. M. Landers, \& J. L. Etnier, 2000). The present study compared mood responses of older people in STP and MTP and showed no significant differences between these exercise modalities indicating that both (STP and MTP) could be used for older populations under the perspective of mood responses considering that both interventions were similar for this variable.

Previous studies showed that strength training might be beneficial for mood responses. For example, McLafferty et al. (2004) verified the effect of 24 weeks of strength training on mood responses of elderly individuals. The exercise sessions were performed three times per week, and the authors observed an improvement in the total mood disturbance of POMS. The present study showed no significant effects of MTP when compared to STP or from pre-to-post analyses.
One possible explanation for the absence of significant effect from pre-to-post measurements is the total duration of our study (16 weeks -48 exercise sessions) when compared to McLafferty et al. (2004) (24 weeks - 72 exercise sessions). Another possible explanation is the involvement with exercise prior to the beginning of the study (at least six months), which may lead to the adaptation and improvement of mood responses of the participants, minimizing the additional effects of STP and MTP. Although no significant differences were observed, this could be interpreted as a positive result, considering that mood responses did not reduce during the training period. In this context, the lack of a control group is a limitation of the present study. However, due to the several benefits provided by exercise, it would not be appropriate to interrupt the exercise routine already performed by the participants of the present study.

Also, no effect between both interventions (STP and MTP) was observed. To our knowledge, none study compared the chronic effect of STP and MTP on mood responses of the elderly, and this result may indicate that both interventions could be used for the elderly, at least for the maintenance of mood responses. However, with respect to the magnitude-based inference, controversial results were observed. MTP was likely beneficial to reduce fatigue. On the other hand, MTP was possibly harmful to increase confusion and to reduce vigor. From these data, the most important was the chance of MTP to reduce fatigue (93\% of chance) compared to STP. Considering that fatigue sensation is associated with negative feelings such as negative affective responses (Ramalho Oliveira, Viana, Pires, Junior Oliveira, \& Santos, 2015), the MTP could be used as a strategy to promote lower disturbances in the mood responses. With respect to depression, tension, hostility, and TMD, an unclear effect was observed. Therefore, in a practical approach, it would not be different to perform STP or MTP for depression, tension, hostility, and TMD.

Some limitations should be considered in the interpretation of the results. The lack of a 


\section{Oliveira et al.}

control group, the small sample size, and the lack of an objective measurement of physical activity in order to determine the level of participants. In addition, the instrument used in the study has been criticized (Ekkekakis, 2013) and maybe a limitation of the study.

\section{CONCLUSION}

In practical terms, due to the similar mood responses observed between STP and MTP, we can conclude that older people physically active seems to attain an adaptation in mood responses minimizing the additional effects of STP and MTP. Also, MTP may be used as an alternative to STP in order to minimize fatigue responses. Health and exercise professionals should encourage the elderly do adopt healthy behaviors, such as exercising regularly, endorsing in different types of programs to increase mood. In order to provide a better understanding of the effects of MTP on mood responses, future studies comparing other interventions such as aerobic exercise, different training program durations (e.g., 30 weeks vs. 40 weeks), and using physically inactive participants are welcome.

\section{ACKNOWLEDGMENTS}

Sergio Machado was supported by the Carlos Chagas Foundation for the Research Support in the State of Rio de Janeiro [FAPERJ] under grant [number E26/203.295/2017].

\section{CONFLICT OF INTEREST STATEMENT}

The authors declare that they have no conflict of interests.

\section{REFERENCES}

1. Agüera-Ortiz, L., Claver-Martín, M. D., Franco-Fernández, M. D., López-Álvarez, J., Martín-Carrasco, M., Ramos-García, M. I., \& Sánchez-Pérez, M. (2020). Depression in the Elderly. Consensus Statement of the Spanish Psychogeriatric Association. 11(380). doi:10.3389/fpsyt.2020.00380

2. Arent, S. M., Landers, D. M., \& Etnier, J. L. (2000). The effects of exercise on mood in older adults: a meta-analytic review. J Aging Phys Act, 8(4), 407430. doi:10.1123/japa.8.4.407

3. Batterham, A. M., \& Hopkins, W. G. (2005). Making meaningful inferences about magnitudes. Int J Sports Physiol Perform, 1(1), 50-57.

4. Bherer, L. (2015). Cognitive plasticity in older adults: effects of cognitive training and physical exercise. Ann N Y Acad Sci, 1337, 1-6. doi:10.1111/nyas.12682

5. Buch, A., Kis, O., Carmeli, E., Keinan-Boker, L., Berner, Y., Barer, Y., . . . Stern, N. (2017). Circuit resistance training is an effective means to enhance muscle strength in older and middle aged adults: A systematic review and meta-analysis. Ageing Res Rev, 37, 16-27. doi:10.1016/j.arr.2017.04.003

6. Cohen, J. (1988). Statistical power analysis for the behavioral sciences (2nd ed.). Hillsdale (MI): Lawrence Erlbaum.

7. Eggenberger, P., Theill, N., Holenstein, S., Schumacher, V., \& de Bruin, E. D. (2015). Multicomponent physical exercise with simultaneous cognitive training to enhance dual-task walking of older adults: a secondary analysis of a 6-month randomized controlled trial with 1-year follow-up. Clin Interv Aging, 10, 1711-1732. doi:10.2147/CIA.S91997

8. Ekkekakis, P. (2013). The measurement of affect, mood, and emotion: a guide for health-behavioral research. New York: Cambridge University Press.

9. Kekalainen, T., Kokko, K., Sipila, S., \& Walker, S. (2018). Effects of a 9-month resistance training intervention on quality of life, sense of coherence, and depressive symptoms in older adults: randomized controlled trial. Qual Life Res, 27(2), 455-465. doi:10.1007/s11136-017-1733-Z

10. Levin, O., Netz, Y., \& Ziv, G. (2017). The beneficial effects of different types of exercise interventions on motor and cognitive functions in older age: a systematic review. Eur Rev Aging Phys Act, 14, 20. doi:10.1186/s11556-017-0189-z

11. Marzetti, E., Calvani, R., Tosato, M., Cesari, M., Di Bari, M., Cherubini, A., . . Consortium, S. (2017). Sarcopenia: an overview. Aging Clin Exp Res, 29(1), 11-17. doi:10.1007/s40520-016-0704-5

12. McLafferty, C. L., Jr., Wetzstein, C. J., \& Hunter, G. R. (2004). Resistance training is associated with improved mood in healthy older adults. Percept Mot Skills, $\quad 98(3 \quad \mathrm{Pt} \quad 1), \quad 947-957$. doi:10.2466/pms.98.3.947-957 


\section{Exercise, mood and life quality in eldely}

13. Piccirilli, M., Pigliautile, M., Arcelli, P., Baratta, I., \& Ferretti, S. (2019). Improvement in cognitive performance and mood in healthy older adults: a multimodal approach. Eur J Ageing, 16(3), 327-336. doi:10.1007/s10433-019-00503-3

14. Ramalho Oliveira, B. R., Viana, B. F., Pires, F. O., Junior Oliveira, M., \& Santos, T. M. (2015). Prediction of Affective Responses in Aerobic Exercise Sessions. CNS Neurol Disord Drug Targets, 14(9), 1214-1218. doi:10.2174/1871527315666151111121924

15. Seitz, D. P., Adunuri, N., Gill, S. S., \& Rochon, P. A. (2011). Prevalence of dementia and cognitive impairment among older adults with hip fractures. J Am Med Dir Assoc, 12(8), 556-564. doi:10.1016/j.jamda.2010.12.001

16. U. S. Department of Health and Human Services (2017). Depression and Older Adults. Retrieved from https://www.nia.nih.gov/health/depression-and-olderadults.

17. Tsutsumi, T., Don, B. M., Zaichkowsky, L. D., \& Delizonna, L. L. (1997). Physical fitness and psychological benefits of strength training in community dwelling older adults. Appl Human Sci, 16(6), 257-266. doi: 10.2114/jpa.16.257

18. Tsutsumi, T., Don, B. M., Zaichkowsky, L. D., Takenaka, K., Oka, K., \& Ohno, T. (1998). Comparison of high and moderate intensity of strength training on mood and anxiety in older adults. Percept Mot Skills, 87(3 Pt 1), 1003-1011. doi:10.2466/pms.1998.87.3.1003

19. Viana, M. F., Almeida, P. L., \& Santos, R. C. (2001). Adaptação portuguesa da versão reduzida do Perfil de Estados de Humor: POMS. Análise Psicológica, 19(1), 77-92. 